\title{
Relationship between core stability, dynamic balance and jumping performance in soccer players
}

\section{Tarik OZMEN}

Department of Physiotherapy and Rehabilitation, School of Health, Karabuk University

Address Correspondence to T.Ozmen, e-mail; tarikozmen@karabuk.edu.tr

Abstract of this study was presented orally at VIII. National Congree of Sport Physiotherapists, November 6-8, 2015, İstanbul.

\begin{abstract}
The purpose of this study was to investigate relationship between core stability, dynamic balance and jumping performance in soccer players. Seventeen male soccer players (mean \pm SD: age, $21.06 \pm 1.71$ years) participated as volunteer in this study. Dynamic balance of the participants were evaluated at directions of anterior (A), posteromedial (PM) and posterolateral (PL) with Star Excursion Balance Test (SEBT). The core stability was evaluated with trunk flexion, side bridge, and trunk extension tests. For jumping performance, squat jump height was measured using a contact mat. There was a negative correlation $(r=-0.705)$ between trunk flexion test and squat jump height $(p<0.002)$. No significant correlation were identified between trunk flexion, side bridge, trunk extension tests and squat jump height $(p>0.05)$. There was no significant correlation between trunk flexion, side bridge, trunk extension tests and SEBT values $(p>0.05)$. The results of this study suggest that trunk flexion is associated with squat jump height in soccer players, but not side bridge and trunk extension tests. The core stability does not contribute significantly on dynamic balance.
\end{abstract}

Keywords: Core stability, balance, jumping, soccer.

\section{INTRODUCTION}

The core has been described as a muscular cylinder with the abdominals in the front, erector spinae and gluteals in the back, the diaphragm as the roof, and the pelvic floor and hip girdle musculature in the bottom (2). The core is the center of the functional kinetic chain providing the proximal stability for the distal mobility and function of the limbs $(8,19)$. The core stability is essential to prevent injuries $(10,20)$ and improve performance in athletes. Weak core muscles may be a risk factor for low back pain (9). Zazulak et al. (21) reported that trunk displacement was greater in athletes with knee and ACL injuries compared with uninjured athletes. It has been reported that core muscle fatigue decreased dynamic stability of the trunk and loss of balance control $(3,6,18)$. Dynamic balance is define as the ability of an individual to maintain stability of the center of mass during movement and an essential component of many sports activities. Dynamic balance is required for activities of daily living, such as walking, running, and stair climbing. Also, it is an important factor associated with lower extremity injury and performance in athletes (7). Soccer game is required a good postural control during efforts such as kick, dribble, pass and to recover quickly after sprints, jumps and cutting maneuvers (15). Soccer is one of the most popular sports in the world, with more than 265 million players. Injury rate in male soccer players has been reported to be as high as 18.75 injuries per 1000 athlete-exposures in competitions and trainings. In both games and trainings, more than two thirds of soccer injuries occurred to the lower extremities, followed by the head and neck in games and the trunk in trainings (1).

Few studies investigated relationship between core stability and athletic performance in soccer players. Nesser et al. (14) reported that there were no significant relationship between core stability and performance tests such as sprint, vertical jump, squat, shuttle run in female soccer players. In contrast, Nesser et al. (13) found significant relationship between core stability and sprint, vertical jump, agility in male soccer players. Sharrock et al. (17) demonstrated that the core stability negatively affected medicine-ball throwing performance in basketball, voleyball, soccer, swimming and tennis athletes. Researchers found no 
significant relationship between core stability and agility, vertical jump, sprint performance.

To our knowledge, the soccer players need to good dynamic balance, core stability, and jumping performance for dribbling, crossing rival, and to be effective in high balls during soccer game. There is no study investigating relationship between core stability and dynamic balance in soccer players. Therefore, the aim of this study was identify relationship between core stability, dynamic balance and jumping performance in soccer players.

\section{MATERIAL \& METHOD}

Seventeen male soccer players (mean age: 21.06 \pm 1.71 years) participated in this study. None of the participants reported any medical or orthopedic problems that would compromise during testing performance. All participants completed Star Excursion Balance Test (SEBT), core endurance tests, and squat jump test during off-season. Descriptive characteristics are given in Table 1.

Table 1. Descriptive characteristics of participants .

\begin{tabular}{lcc}
\hline & Mean & SD \\
\hline Age (year) & 21.06 & 1.71 \\
Height $(\mathrm{cm})$ & 178.41 & 4.70 \\
Weight $(\mathrm{kg})$ & 70.82 & 5.94 \\
Sport experince (year) & 7.12 & 3.91 \\
\hline
\end{tabular}

\section{Dynamic Balance}

The dynamic balance of participants were evaluated with the SEBT. Leg length was used to normalize excursion distances by dividing the distance reached by leg length and then multiplying the result by 100 . Leg length was measured from the anterior superior iliac spine to the most prominent bony point of the ipsilateral medial malleolus with a standard tape measure while subjects lay supine on a bed. The reach directions were determined by affixing three tape measures to the floor, one orientated anterior to the apex (A) and two aligned at $135^{\circ}$ to this in the posteromedial (PM) and posterolateral (PL) directions. Each subject was instructed to reach as far as with the non-dominant leg in each of the 3 directions while maintaining dominant-leg stance. The dominant leg was determined by asking which leg would be their take-off leg in a lunge or jump. High inter-tester and intra-tester reliability of the SEBT has previously been reported (17).

\section{Core Stability}

The protocol established by McGill (18) was used to determine core muscles endurance. For the side bridge test (SBT), subjects lay on their side with their legs extended on a bed, resting on their forearm with the elbow flexed to $90^{\circ}$. Participants were instructed to lift the hip off the table with the other arm and hand across the chest resting on the opposite shoulder. The test was terminated when straight body position could no longer be maintained. Time was recorded in seconds using a stopwatch. For the trunk flexion test (TFT), the subjects were seated with their back resting against a wedge that maintained $45^{\circ}$ flexion from the horizontal on the treatment table. Knees were flexed to $90^{\circ}$ and the feet stabilized by a researcher. The test was terminated when the upper body could no longer remain at the $45^{\circ}$ angle. Time was recorded in seconds using a stopwatch. For trunk extension test (TET), the subjects laid on the treatment table in a prone position with the upper body cantilevered out over the end of the table. Subjects were asked to maintain a horizontal body position with arms crossed across the chest while a researcher stabilized the lower extremities. The test was terminated when the subject fell below the horizontal position. Time was recorded in seconds using a stopwatch.

\section{Jumping Performance}

Jumping height of participants were measured with squat jump test using a contact mat (Swift Performance Equipment, Lismore, NSW, Australia). Each participant jumped with $90^{\circ}$ knee flexion, barefoot, and their hands on hips on the mat. held that position for four seconds before jumping for maximum height. The best score of two jumping effort was recorded.

\section{Statistical Analysis}

The SPSS 16.0 software (SPSS Inc., Chicago, Ill) was used for data analysis. Standard statistical methods were used for the calculation of means and SD. The Kolmogorov-Smirnov test was used to determine if dependent variables were normally distributed. Relationships between test variables were determined using multiple bivariate correlations, represented by the Pearson correlation coefficient. Statistical significance was set at $p<0.05$. 


\section{RESULTS}

All tested variables of participants were presented Table 2. There was a negative correlation $(r=-0.705)$ between trunk flexion test and jumping height $(p=0.002)$. There was no significant relationship between side bridge, trunk extension tests and jumping height $(p>0.05)$. There was no significant relationship between trunk flexion, side bridge, trunk extension tests and SEBT results $(p>$ $0.05)$. Correlations among all tested variables of participants were presented Table 3.

Table 2. All tested variables of participants (mean \pm SD).

\begin{tabular}{lcc}
\hline Variable & Mean & SD \\
\hline A & 79.71 & 11.86 \\
PM & 99.29 & 10.18 \\
PL & 92.29 & 10.26 \\
Trunk flexion & 160.00 & 66.85 \\
Lateral bridge & 52.82 & 22.27 \\
Back extension & 129.24 & 39.64 \\
Squat jump & 34.50 & 1.59 \\
\hline
\end{tabular}

Abbreviations: A, Anterior; PM, Posteromedial; PL, Posterolateral

\section{DISCUSSION}

The results of this study showed that trunk flexion is negatively associated with squat jump height, but not side bridge and trunk extension tests. The jumping performance requires explosive power of lower extremity muscles including activation of the fast twitch muscle fibers. However, core muscles contract isometrically for a longer time period than jumping activity during core endurance tests and slow-twitch muscle fibers are active. This may be an explanation that there is insufficient relationship between core endurance and squat jump height. Our results were similar to those of Nesser et al. (14), who investigated the relationship between core muscle strength and athletic performance in sixteen female soccer players. The researchers evaluated core muscle strength with side bridge, trunk flexion and trunk extension tests. They reported that there was no found significant correlation between core stability and performance tests such as one repetition maximum (1 RM) squat, 1RM bench press, vertical jump, 40 yard sprint, 10 yard shuttle run test. Sharrock et al. (17) demonstrated that there was no found significant relationship between core stability and agility, vertical jump, sprint performance in basketball, voleyball, soccer, swimming and tennis athletes. They used bent knee lowering test to examine core stability. In contrast, Nesser et al. (13) showed that there was a moderate level relationship between core stability and $20 \mathrm{~m}$ sprint, vertical jump, and agility in twenty-nine male soccer players.

Our finding showed that core stability was no associated with dynamic balance. Many activities of daily living and sports are classified as dynamic activities. Therefore, in this study, to assess dynamic balance rather than static balance was considered. In the present study, dynamic balance of participants were evaluated with selected directions of the SEBT. The SEBT is a quick and inexpensive method commonly used by many researchers to identify dynamic balance deficits in patients and to be responsive to training programs in athletes with and without injuries to the lower extremity (7). This test requires the participant to reach along three line with one leg while standing on the other leg. The SEBT performance may be affected by kinetic and kinematic factors such as the range of motion of the knee and hip joints, flexibility and strength of the lower extremity muscles $(4,5,16)$. In addition, postural control and maintenance of balance is a complex process by which different systems worked collectively. These are the central nervous system comprising brain and spinal cord, peripheral nervous sytem comprising afferent and efferent pathways, musculoskeletal system, sensory system composed of a variety of sensory receptors, and visual system. In consistent with our results, Gordon et al. (5) reported that core stability was no associated with SEBT values in female lacrosse players. They used only bent knee lowering test to examine core stability.

Table 3. Correlations among all tested variables of participants

\begin{tabular}{|c|c|c|c|c|c|c|c|}
\hline & $\mathrm{A}$ & PM & PL & Trunk flexion & Side bridge & Back extension & Squat jump \\
\hline $\mathrm{A}$ & 1 & 0.807 & 0.788 & 0.361 & 0.099 & 0.439 & 0.065 \\
\hline PM & 0.807 & 1 & 0.927 & 0.320 & 0.087 & 0.281 & -0.040 \\
\hline PL & 0.788 & 0.927 & 1 & 0.403 & 0.055 & 0.253 & -0.047 \\
\hline Trunk flexion & 0.361 & 0.327 & 0.403 & 1 & 0.546 & 0.643 & $-0.705^{*}$ \\
\hline Side bridge & 0.099 & 0.087 & 0.055 & 0.546 & 1 & 0.284 & -0.395 \\
\hline Back extension & 0.439 & 0.281 & 0.253 & 0.643 & 0.284 & 1 & -0.362 \\
\hline Squat jump & 0.065 & -0.040 & -0.047 & -0.705 & -0.395 & -0.362 & 1 \\
\hline
\end{tabular}

Abbreviations: A, Anterior; PM, Posteromedial; PL, Posterolateral. ${ }^{*} p<0.05$ 
In conclusion; trunk flexion is associated with squat jump height in soccer players, but not side bridge and trunk extension tests. The core stability does not contribute significantly on dynamic balance. Soccer is a sport with the greatest participation all over the world. Future studies should investigate between core stability and athletic performance with larger sample size in soccer players. The core strength training in addition to routine training programs may contribute to performance of athletes. The researchers should focus on the effects of core strength training programs on athletic performance in soccer players.

\section{REFERENCES}

1. Agel J, Evans TA, Dick R, Putukian M, Marshall SW Descriptive epidemiology of collegiate men's soccer injuries: National Collegiate Athletic Association Injury Surveillance System, 1988-1989 through 2002-2003. Journal of Athletic Training, 2007; 42(2): 270.

2. Akuthota V, Ferreiro A, Moore T, Fredericson M. Core stability exercise principles. Current sports medicine reports, 2008; 7(1): 39-44.

3. Davidson BS, Madigan ML, Nussbaum MA. Effects of lumbar extensor fatigue and fatigue rate on postural sway. European Journal of Applied Physiology, 2004; 93:183-189.

4. Earl JE, Hertel J. Lower-extremity muscle activation during the Star Excursion Balance Tests. Journal of Sport Rehabilitation, 2001; 10(2): 93-104.

5. Gordon AT, Ambegaonkar JP, Caswell SV. Relationships between core strength, hip external rotator muscle strength, and star excursion balance test performance in female lacrosse players. International Journal of Sports Physical Therapy; 2013: 8(2), 97.

6. Granata KP, Gottipati P. Fatigue influences the dynamic stability of the torso. Ergonomics, 2008; 51(8): 1258-1271.

7. Gribble PA, Hertel J, Plisky P. Using the Star Excursion Balance Test to assess dynamic postural-control deficits and outcomes in lower extremity injury: a literature and systematic review. Journal of Athletic Training, 2012; 47(3): 339-357.

8. Kibler WB, Press J, Sciascia A. The role of core stability in athletic function. Sports medicine, 2006; 36(3): 189-198.

9. Lee JH, Hoshino Y, Nakamura K, Kariya Y, Saita K, Ito K. Trunk Muscle Weakness as a Risk Factor for Low Back Pain: A 5-Year Prospective Study. Spine, 1999; 24(1): 54-57.
10. Leetun DT, Ireland ML, Willson JD, Ballantyne BT, Davis IM. Core stability measures as risk factors for lower extremity injury in athletes. Medicine \& Science in Sports \& Exercise, 2004; 36(6): 926-934.

11. McGill SM, Childs A, Liebenson C. Endurance times for low back stabilization exercises: clinical targets for testing and training from a normal database. Archives of Physical Medicine and Rehabilitation, 1999; 80(8): 941-944.

12. Munro AG, Herrington LC. Between-session reliability of the star excursion balance test. Physical Therapy in Sport, 2010; 11(4): 128-132.

13. Nesser TW, Huxel KC, Tincher JL, Okada T. The relationship between core stability and performance in division I football players. The Journal of Strength \& Conditioning Research, 2008; 22(6): 1750-1754.

14. Nesser TW, Lee WL. The relationship between core strength and performance in division I female soccer players. Journal of Exercise Physiology Online, 2009; 12(2): 21-28.

15. Pau M, Arippa F, Leban B, Corona F, Ibba G, Todde F, Scorcu M. Relationship between static and dynamic balance abilities in Italian professional and youth league soccer players. Physical Therapy in Sport, 2014; 16(3): 236-241.

16. Robinson R, Gribble P. Kinematic predictors of performance on the Star Excursion Balance Test. Journal of Sport Rehabilitation, 2008; 17(4): 347-357.

17. Sharrock C, Cropper J, Mostad J, Johnson M, Malone T. A pilot study of core stability and athletic performance: is there a relationship?. International Journal of Sports Physical Therapy, 2011; 6(2), 63.

18. Van Dieën JH, Luger T, van der Eb, J. Effects of fatigue on trunk stability in elite gymnasts. European Journal of Applied Physiology, 2012; 112(4): 1307-1313.

19. Willardson JM. Core stability training for healthy athletes: a different paradigm for fitness professionals. Strength \& Conditioning Journal, 2007; 29(6): 42-49.

20. Willson JD, Dougherty CP, Ireland ML, Davis IM. Core stability and its relationship to lower extremity function and injury. Journal of the American Academy of Orthopaedic Surgeons, 2005; 13(5): 316-325.

21. Zazulak BT, Hewett TE, Reeves NP, Goldberg B, Cholewicki J. Deficits in neuromuscular control of the trunk predict knee injury risk a prospective biomechanical-epidemiologic study. The American journal of sports medicine, 2007; 35(7): 11231130 . 